\title{
EDITORIAL
}

nature

cell biology

\section{Missed opportunity to ban reproductive cloning}

After years of diplomatic wrangling, in March the UN general assembly voted 84 to 34 (with 37 abstentions) in favour of a nonbinding resolution that urges member nations to adopt a blanket ban on all forms of human cloning. This declaration was proposed by Honduras - generally thought to be at the behest of the US government and the vote was largely carried by predominantly Roman Catholic countries, in line with Pope John Paul II's views on the matter. The opposing minority was represented by countries with more liberal approaches to the ethical quagmire thrown up by this issue. Many of these, including eastern Asian countries and several European countries, are pursuing active stem cell research programmes. Islamic countries were well represented among the abstentions, in line with their previous 'wait and see' approach to cloning.

President Bush, who had suggested this line of policy last autumn during a speech to the general assembly, did not wait long to applaud the resolution, citing the importance of protecting "human life" and "human dignity". Meanwhile, the UK's representatives gave an uncharacteristically blunt rebuke of these views; ambassador Jones Parry commented that "the declaration ... is a weak, nonbinding statement that does not reflect anything approaching a consensus ... nor will it affect the UK's strong support of stem cell research". Indeed, the UK had made up its mind well in advance of the vote to ignore the outcome, and pushes ahead with significantly bolstered funding for medical research, with a declared emphasis on stem cells.

The UK government's viewpoint is shared by the Royal Society. Richard Gardener, chairman of its working group on stem cell research and cloning, called the declaration "ambiguous and badly worded...frustrating and disappointing," citing the support of 67 other science academies for a policy that bans reproductive cloning, but allows individual countries to decide on somatic cell nuclear transfer procedures, commonly referred to as 'therapeutic cloning'.

Importantly, the declaration is ultimately a watered-down compromise that has no legal implications. The UN has again failed to institute formal hurdles to prevent what everyone agrees on in principle - a binding global ban of human reproductive cloning. Notably, a broadly backed proposal to this effect was first made by France and Germany back in 2001. At a critical time, the UN has thus failed to send a clear message that human reproductive cloning is unacceptable. It is lamentable that this salient issue has fallen victim to a debate that is driven by political agenda and religion-infused ethics, rather than rational thinking that puts the patient's interests first. The therapeutic promise of all stem cell research is beyond doubt. At this time, it is essential to pursue embryonic stem cell research, which holds some of the greatest medical promise, and to keep an open mind to therapeutic cloning. Scientists and informed politicians do of course realize this, which is why embryonic stem cell research is being vigorously pursued - not least across the US, either with private funding or in states such as California and New Jersey, which have set up independent financing initiatives.

It seems futile at present to encourage a reappraisal in Washington of how ethically charged decisions such as embryonic stem cells and abortion areinformed. However, itisessential tokeep thepublicinformed of the medical realities of stem cell research, since ultimately it is public support that will sway political decisions in a democratic system. This is also true in Europe, where religious conservativism is becoming more vociferous. Abortion and stem cell research, for example, are likely to become key topics for debate in the upcoming UK general elections.

Aside from the ethical debate surrounding therapeutic cloning, stem cells have arguably become the new 'miracle cure for all'. Internationally consistent medical regulation is urgently needed to ensure that medical application continues apace with scientific advances. Only then can charlatans or overly naïve medical practitioners be prevented from seizing on high public expectations. There are ample clinical trials that promise applications of stem cells for regenerative medicine; for example, the use of bone marrow stem cells to treat heart disease. However, even in well studied areas such as this, the efficacy of the treatments remains hotly debated, and many scientists warn that clinical application remains premature - and possibly dangerous - in light of the lack of understanding of the science underlying clinical trials.

A good example is India, which has been encouraging embryonic stem cell research. Recent reports suggest that both private and publicly funded clinicians in India are only too eager to apply what they regard as stem cell therapy to conditions such as heart disease, diabetes, muscular dystrophy and cerebral palsy (Nature 434, 259). This work is not published and there is considerable confusion as to what sort of cell preparations are being applied, or even what the patient outcome is. The Indian Council for Medical Research (ICMR) and the Department of Biotechnology (DBT), the two government agencies in charge of regulating such research, seem to be unaware of many of the medical procedures that are already applied, and they are only now attempting to issue consistent guidelines for clinical practise. The World Health Organization (WHO) should be encouraged to take a more active role in informing and regulating medical application of stem cells before the holy grail of regenerative medicine looses public support on account of premature and failed clinical application.

In the meantime, the only lasting effect that the UN resolution may have is to drive further apart the two sides of the embryonic stem cell debate; in a sense, the internal divisions within the US are thus projected globally. A further consequence of the resolution is that the UN has demonstrated an inability to make strong decisions on the basis of a rational and scientifically informed argument, leaving this critically important institution looking the weaker for it. 